\title{
Online Educational Tools for Caregivers of People with Dementia: A Scoping Literature Review
}

Richard Sztramko, $\mathrm{MD}^{1,3}$, Anthony J. Levinson, MD, MA, MSc ${ }^{2,3}$, Andrea E. Wurster, MSc, $\mathrm{BA}^{3,4}$, Rita Jezrawi, MSc, BA ${ }^{4}$, Branavan Sivapathasundaram, MPH, BSc ${ }^{3}$, Alexandra Papaioannou, MD, MSc, BSCN ${ }^{1,3,4}$, David Cowan, $\mathrm{MD}^{1,3}$, Joye St. Onge, $\mathrm{MD}^{1,3}$, Sharon Marr, $\mathrm{MD}^{1,3}$, Christopher Patterson, $\mathrm{MD}^{1,3}$, Tricia Woo, MD, MSc ${ }^{1,3}$, Lori Mosca, $\mathrm{MBA}^{2}$, Cynthia Lokker, PhD, $\mathrm{MSc}^{4}$

${ }^{1}$ Division of Geriatric Medicine, Department of Medicine, McMaster University, Hamilton; ${ }^{2}$ Division of e-Learning Innovation, Faculty of Health Sciences, McMaster University, Hamilton; ${ }^{3}$ GERAS Centre, St. Peter's Hospital, Hamilton; ${ }^{4}$ Department of Health Research Methods, Evidence, and Impact, McMaster University, Hamilton, ON

https://doi.org/10.5770/cgj.24.506

\begin{abstract}
\section{Background}

Informal caregivers of people with dementia provide the majority of health-based care to people with dementia. Providing this care requires knowledge and access to resources, which caregivers often do not receive. We set out to evaluate the effect of online educational tools on informal caregiver self-efficacy, quality of life, burden/stress, depression, and anxiety, and to identify effective processes for online educational tool development.
\end{abstract}

\section{Methods}

We conducted a scoping review of articles on online educational interventions for informal caregivers of people with dementia searching CINAHL, MEDLINE, EMBASE, and PubMed from 1990 to March 2018, with an updated search conducted in 2020. The identified articles were screened and the data were charted.

\section{Results}

33 articles that reported on 24 interventions were included. There is some evidence that online interventions improve caregiver-related outcomes such as self-efficacy, depression, dementia knowledge, and quality of life; and decrease caregiver burden. Common findings across the studies included the need for tailored, stage-specific information applicable to the caregiver's situation and the use of psychosocial techniques to develop the knowledge components of the interventions.

\section{Conclusion}

We demonstrate the importance of having caregivers and health-care professionals involved at all stages of tool conceptualization and development. Online tools should be evaluated with robust trials that focus on how increased knowledge and development approaches affect caregiver-related outcomes.
Key words: online intervention; dementia; caregiver; educational; eHealth; support services

\section{INTRODUCTION}

There are more than half a million Canadians living with dementia, with this number expected to reach 912,000 in the next 10 years. ${ }^{(1)}$ One in five Canadians care for someone living with dementia with an annual cost estimated at $\$ 12$ billion CAD ${ }^{(1)}$ Currently, informal caregivers (family members and friends) provide the majority of health-based care for people with dementia (PwD). ${ }^{(2)}$ Caregivers of PwD are at increased risk for depression, anxiety, financial distress, isolation, and cardiovascular events. ${ }^{(2)}$ Caregivers have identified interrelated needs that are important to their caregiving roles which include: emotional and social support; receiving accessible information that improves their knowledge of dementia, their care skills, and coping strategies; being trained and educated to provide care; and learning how to balance caregiving duties with their own needs. ${ }^{(3)}$

Online educational tools or programs are needed to support the caregiver experience with respect to knowledge or skill acquisition, and obtaining meaningful informal (community, friends, and family) and formal supports (day programs, paid personal support or nursing care). These programs should aim to reduce the physical, mental, and financial consequences of caregiving.

A previous needs assessment at our geriatric clinic identified that caregivers perceive that educational information is not customized or readily available. ${ }^{(2)}$ Current sources of information are either too simplistic or overwhelming for different styles of learning; some caregivers want to have resources conveniently available when they need to review. ${ }^{(2)}$ Some resources found online by caregivers are insufficient for their needs or are not evidence-based. ${ }^{(2)}$ In particular, 
caregivers are looking for information and resources which meet the approval of their health-care providers and are clearly deemed trustworthy. ${ }^{(2)}$ Recent systematic reviews and meta-analyses have found some evidence of positive effects of online interventions for caregivers of PwD, particularly for outcomes of caregiver stress, ${ }^{(4)}$ self-efficacy, ${ }^{(4)}$ burden, ${ }^{(5-9)}$ and depression/anxiety. ${ }^{(4-7,9,10)}$ Multi-component interventions show the strongest effects. ${ }^{(6,8-10)}$

The purpose of this scoping review was to summarize the evidence on the effectiveness of existing online educational programs for caregivers of PwD on caregiver self-efficacy, depression, and stress/burden. To better understand how education programs with published evidence are structured and how they were developed, a secondary objective was to explore educational tool features and design approaches, including involvement of caregivers, interface usability, instructional design best practices, and accessibility in the context of technologic and cultural barriers in the aging population.

\section{METHODS}

We used a scoping review framework to identify the research questions, search and select relevant studies, and chart and summarize the results from each study. ${ }^{(11)}$ We searched MEDLINE, CINAHL, and EMBASE from 1990 to March 2018. To identify new evidence since the original search, we conducted a supplemental search of articles in MEDLINE up to July 2020. We used the following MeSH terms: "dementia" (including dementia as a keyword), "caregivers", "telemedicine" (including eHealth as a keyword), "Programmed Instruction as Topic", and "Software." Each MeSH term was exploded, and all sub-headings were included. The following terms were used as keywords: "Alzheimer*", "caregiv*", "carer*", "eLearning", "online intervention", "mobile app", "Dementia”, "telemedicine", and "Internet". Terms were translated for each of the databases (Appendix A).

The search strategy was developed with the guidance of a professional librarian; we were advised to include all study designs and mediums to cast a wider net on the search, explore the specifications of various interventions, and exclude irrelevant studies thereafter. The inclusion criteria were English-language peer-reviewed research articles describing or evaluating any web- or internet-based educational interventions for informal caregivers of $\mathrm{PwD}$ (of any age, sex, or geographic location) that provided information about dementia and resources or services to enhance their caregiving or coping skills. Randomized controlled trials (RCTs), mixed methods, observational, or qualitative study designs were included. Based on availability of the internet, we defined 1990 as the beginning timeframe of our search. Exclusion criteria were interventions focused on caregivers of people with other illnesses, non-web- or internetbased educational tools, online psychosocial or social support groups, smart home or smart phone applications, telemedicine or telecounselling, targeted at PwD rather than their caregivers, focus on formal/paid caregiver population, or articles which did not measure our outcomes of interest.
The primary pre-specified outcome of interest was caregiver self-efficacy. Secondary outcomes included caregiver quality of life, burden, distress, stress, depression, anxiety, and process outcomes related to tool development. During the search, we found that dementia knowledge, goal-setting, competence, and relationship strain were common concepts related to behavioural change and the needs of caregivers. We included them as additional secondary outcomes during the interpretation and analysis phase, as they were interrelated with our pre-specified primary and secondary outcomes.

All articles were downloaded into RefWorks; titles and abstracts were screened in duplicate (AW and BS). Data were extracted by AW and checked for accuracy by BS. Disagreements were solved between the two reviewers (AW and BS) and, when necessary, a third author (RS). Details of the intervention, study methods including outcome scales that were used, intervention design approaches, and results were abstracted and mapped.

\section{RESULTS}

The search yielded 1,237 articles; 601 remained after removal of duplicates. After title and abstract screening, 85 full-text articles were screened in duplicate for eligibility. We identified 28 articles that met inclusion criteria, and 3 RCTs were identified from reference lists during data extraction; 32 studies, of which 11 were RCTs, were included in the review. ${ }^{(12-41,42,43,)}$ We included one relevant article out of 364 potential articles from the supplemental updated search and one article through reference checking. ${ }^{(44,45)}$ Figure 1 shows the PRISMA flow diagram. As this is a scoping review, we did not assess the quality of all study types and we did not perform any pooled analysis. The 33 included studies (Appendix B) reported on 24 online educational programs (details of program features in Appendix C). The key components featured in the programs are reported in Table 1.

\section{Outcomes}

Many articles evaluated the usability and usefulness of the program and caregiver-attitudes towards the program (Appendix 2). Eighteen articles measured the comparative effectiveness of the intervention, in RCTs, mixed methods, or pre-post-test pilots, reporting caregiver-relevant outcomes. ${ }^{(12,14,15,17,20,22,23,25-33,44,45)}$ Key outcomes of interest reported across studies included self-efficacy, depression, anxiety, and quality of life of the caregivers; dementia knowledge, goal-setting, competence and mastery; relationship strain. There was considerable variability in the results across interventions; studies reported statistically significant positive improvement in relationship strain, ${ }^{(15,25)}$ stress, ${ }^{(25,27,45)}$ competence, ${ }^{(12,14,32)}$ quality of life, ${ }^{(12)}$ or dementia knowledge. ${ }^{(26,31-33)}$

\section{Self-efficacy}

Six studies measured self-efficacy and used the Revised Scale for Caregiver Self-Efficacy. ${ }^{(12,14,25,26,30,45)}$ Significant improvement was reported in the Partners in Balance (PIB) 


\section{SZTRAMKO/LEVINSON: ONLINE EDUCATIONAL TOOLS FOR DEMENTIA CAREGIVERS}

and Caregiver's Friend interventions, while the remaining studies did not report significant improvements. ${ }^{(14,25)}$

\section{Stress and Burden}

Twelve studies measured stress or burden and used the Zarit Burden Interview or the Perceived Stress Scale. ${ }^{(14,20,22-27,29,38,44,45-47)}$ Only three studies reported a statistically significant reduction in perceived stress. ${ }^{(25,27,45)}$ Tele-Savvy was the only intervention to a report statistically significant reductions in burden. ${ }^{(44)}$

\section{Depression}

Eleven studies measured depression; nine used the Center for Epidemiological Studies Depression Scale, but Diapason used the Beck Depression Inventory. ${ }^{(14,23-30,33,44,48,49)}$ Four studies reported a significant decrease in depressive symptoms, ${ }^{(23,25,28,44)}$ while the remaining articles did not.

\section{Anxiety}

Four studies measured anxiety using the Hospital Anxiety and Depression Scale and a 10-item subscale of the State-Trait Anxiety Inventory, and one study measured emotional status using the Brief Symptom Inventory. ${ }^{(14,23,25,33,38,50-52)}$ Two of the studies found significant improvements in anxiety or emotional status, while the remaining studies did not find significant improvements. ${ }^{(23,25)}$

\section{Perceived Quality of Life}

The DEM-DISC, iCare, PIB, Ginko, and RHAPSODY studies measured perceived quality of life using the World Health Organization Quality of Life measure, the Investigating Choice Experiments for the Preferences of Older People measure, Perceived Quality of Life Scale, and ED-5D-5L health-related quality of life measure; only PIB reported statistically significant improvements, while the other studies did not find any significant improvements. ${ }^{(14,27,30,33,45,53-56)}$

\section{Dementia Knowledge}

Four studies that assessed caregiver-dementia knowledge reported improvements; however, two surveys to assess this were created for the sole purpose of testing the intervention, and one survey was not cited. ${ }^{(26,31-33)}$ One study did not have significant post-test improvements in knowledge. ${ }^{(30)}$

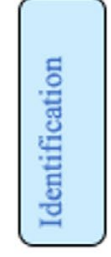

Records identified through database searching $(\mathrm{n}=1237)$

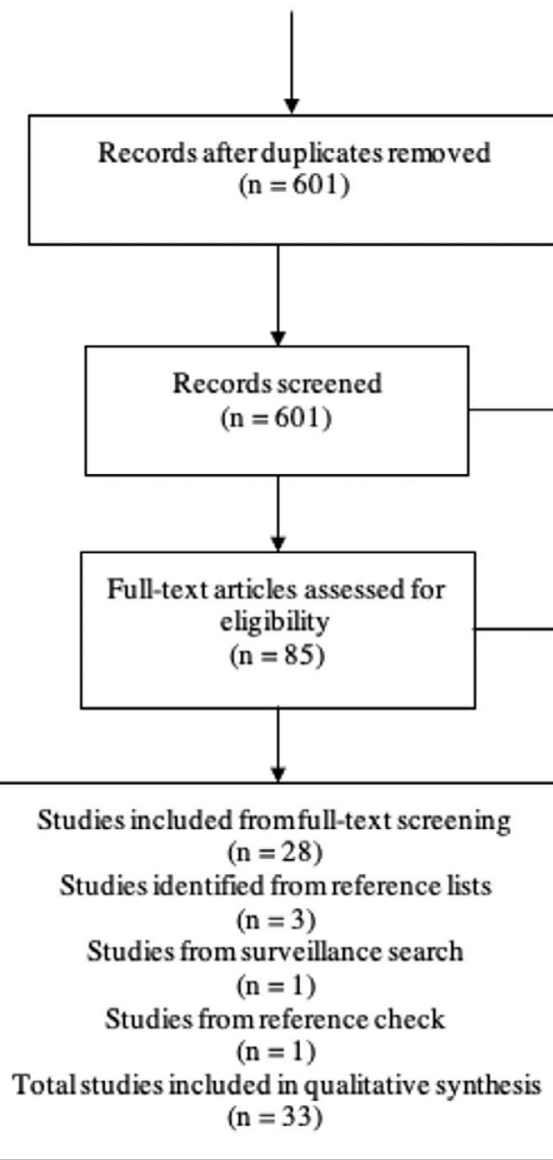

Full-text articles excluded, Formal CGs $(n=4)$ PwD or self-management $(n=4)$ Not online education, were psychosocial in nature, or a smart home or phone application $(\mathrm{n}=28)$, CGs of people with other ailments (n $=1$ )

Could not be retrieved $(\mathrm{n}=10)$, Duplicate publication with a different title $(\mathrm{n}=1)$

Research protocol $(n=7)$

Systematic review $(n=2)$

FIGURE 1. Study flow diagram 
TABLE 1.

Intervention components matrix

\begin{tabular}{|c|c|c|c|c|c|c|c|c|}
\hline & \multicolumn{8}{|c|}{ Component } \\
\hline & Website & $A p p$ & $\begin{array}{l}\text { Delivers } \\
\text { information as } \\
\text { multimedia }^{a}\end{array}$ & $\begin{array}{c}\text { Delivers } \\
\text { informtion } \\
\text { as static text }\end{array}$ & $\begin{array}{l}\text { Digital } \\
\text { forum/ } \\
\text { community }\end{array}$ & $\begin{array}{c}\text { Facilitator/ } \\
\text { email } \\
\text { support }\end{array}$ & $\begin{array}{l}\text { Log-in } \\
\text { required }\end{array}$ & $\begin{array}{l}\text { Publicly } \\
\text { accessible } \\
\text { from web }\end{array}$ \\
\hline \multicolumn{9}{|l|}{ Intervention } \\
\hline Partner in Balance $\mathrm{e}^{(12-14)}$ & $\checkmark$ & & $\checkmark$ & & & & $\checkmark$ & $\checkmark$ \\
\hline ComputerLink $^{(15-18)}$ & & & & $\checkmark$ & $\checkmark$ & $\checkmark$ & & \\
\hline $\begin{array}{l}\text { Internet-Based Support } \\
\text { Services (ICSS) }\end{array}$ & $\checkmark$ & & & $\checkmark$ & & $\checkmark$ & $\checkmark$ & \\
\hline $\begin{array}{l}\text { Mastery Over Dementia } \\
(\mathrm{MoD})^{(23,24)}\end{array}$ & $\checkmark$ & & & & & $\checkmark$ & $\checkmark$ & \\
\hline $\begin{array}{l}\text { Caregiver's Friend: Dealing } \\
\text { with Dementia( } 25)\end{array}$ & $\checkmark$ & & $\checkmark$ & $\checkmark$ & & & & \\
\hline Diapason $^{(26)}$ & $\checkmark$ & & $\checkmark$ & $\checkmark$ & $\checkmark$ & $\checkmark$ & $\checkmark$ & \\
\hline iCare $^{(27)}$ & $\checkmark$ & & $\checkmark$ & & & & & $\checkmark$ \\
\hline UnderstAID $^{(28)}$ & $\checkmark$ & & $\checkmark$ & & & & & \\
\hline Cuidate Cuidator ${ }^{(29)}$ & $\checkmark$ & & & $\checkmark$ & & & $\checkmark$ & \\
\hline DEM-DISC ${ }^{(30)}$ & $\checkmark$ & & & $\checkmark$ & $\checkmark$ & & & \\
\hline CARES for Families ${ }^{(31)}$ & $\checkmark$ & & $\checkmark$ & $\checkmark$ & & $\checkmark$ & $\checkmark$ & $\checkmark$ \\
\hline CARES Dementia Basics ${ }^{(32)}$ & $\checkmark$ & & $\checkmark$ & & & & $\checkmark$ & $\checkmark$ \\
\hline Ginko $^{(33)}$ & $\checkmark$ & & $\checkmark$ & & & $\checkmark$ & & \\
\hline $\begin{array}{l}\text { STAR Training Program } \\
\text { (STAR) }^{(34)}\end{array}$ & $\checkmark$ & & $\checkmark$ & & & & $\checkmark$ & $\checkmark$ \\
\hline $\begin{array}{l}\text { Living and Dying Well with } \\
\text { Dementia: Mobile App } \\
\text { (35) }\end{array}$ & & $\checkmark$ & $\checkmark$ & & & & & $\checkmark$ \\
\hline AlzOnline ${ }^{(36)}$ & $\checkmark$ & & $\checkmark$ & & & $\checkmark$ & & $\checkmark$ \\
\hline $\begin{array}{l}\text { Massive Open Online } \\
\text { Course: Understanding } \\
\text { Dementia }(\mathrm{MOOC})^{(37)}\end{array}$ & $\checkmark$ & & $\checkmark$ & & & $\checkmark$ & $\checkmark$ & $\checkmark$ \\
\hline $\begin{array}{l}\text { An informative website for } \\
\mathrm{CGs}^{(38)}\end{array}$ & $\checkmark$ & & $\checkmark$ & $\checkmark$ & & & $\checkmark$ & \\
\hline Caring for Me and $\mathrm{You}^{(39)}$ & $\checkmark$ & & $\checkmark$ & & & $\checkmark$ & & \\
\hline $\begin{array}{l}\text { Digital Alzheimer's Centre } \\
(\mathrm{DAC})^{(40)}\end{array}$ & $\checkmark$ & & & $\checkmark$ & & $\checkmark$ & $\checkmark$ & \\
\hline Tele-Savvy ${ }^{(41,44)}$ & $\checkmark$ & & $\checkmark$ & & & $\checkmark$ & & \\
\hline $\begin{array}{l}\text { Network Support Dementia } \\
\operatorname{Project}^{(43)}\end{array}$ & $\checkmark$ & & & $\checkmark$ & & $\checkmark$ & $\checkmark$ & \\
\hline $\begin{array}{l}\text { Nurses Improving Care } \\
\text { for Health System Elders } \\
\left(\text { (NICHE) }^{(42)}\right.\end{array}$ & & $\checkmark$ & & $\checkmark$ & & & $\checkmark$ & $\checkmark$ \\
\hline RHAPSODY ${ }^{(45)}$ & $\checkmark$ & & $\checkmark$ & $\checkmark$ & $\checkmark$ & $\checkmark$ & $\checkmark$ & $\checkmark$ \\
\hline
\end{tabular}

${ }^{a}$ Multimedia refer to the use or combination of graphics, audio, or videos with text to deliver content.

bStatic text refers to no multimedia or interactive components (e.g., no videos or quizzes) and passive information delivery. 


\section{Goal-Setting, Competence, and Mastery}

Six studies assessed goal-setting, competence, and mastery. The PIB tool assessed goal attainment through the Goal Attainment Scale. ${ }^{(12,14,57)}$ The Tele-Savvy and Cuidate Cuidador studies assessed mastery and competence through the Personal Mastery Scale. ${ }^{(29,42,58)}$ Lastly, CARES evaluated perceived competence through the Sense of Competence in Dementia Care Staff Scale. ${ }^{(32,59)}$ CARES, Tele-Savvy, and PIB found improved sense of competence, while Mastery over Dementia did not. ${ }^{(12,14,23,32,44)}$

\section{Development of Intervention and Usability Testing}

Most studies (31/33) explained the methodology for intervention development. Interventions were developed by medical experts, social workers, content experts, and professionals such as instructional designers. ${ }^{(22,25,34,35,38)}$ Some interventions were developed with caregivers and PwD input through focus groups, interviews, and/or post-development feedback. ${ }^{(12,25,35,38)}$

Several authors used an iterative-feedback developmental methodology. ${ }^{(19,28,34,36)}$

Caring for Me and You was created as a computerized cognitive behavioural therapy intervention, while Mastery over Dementia was created using an existing self-help cognitive behavioural therapy intervention. ${ }^{(24,39)}$ The Caregiver's Friend and Tele-Savvy interventions used the LazarusFolkman model of stress appraisal and coping as the theoretical foundation to create teleconferences, dramatizations, and video testimonial components of the interventions. Both interventions addressed affective learning, cognitive and behavioural skills, and knowledge about dementia. $25,44,60)$ For instance, modules based on the model of stress appraisal included challenges and rewards of caregiving, coping with emotions, and common difficulties of the care recipient. ${ }^{(25)}$ The framework or foundation of most of the interventions included behaviour change techniques such as coping with behavioural problems, arranging help from others, making time for oneself, and the detection and restructuring of helpful and unhelpful thoughts. ${ }^{(24)}$ Psychological techniques in the studies included psychoeducation, problem-solving, relaxation, cognitive restructuring, emotional validation and time management. $(22,24,26,31,33,44)$

Articles which focused on assessing the usability of the interventions STAR and ICSS used task-instructed methods, measuring eye gaze and mouse movements, and think-a-loud methods. ${ }^{(19,34)}$ In both interventions, participants could mostly complete the tasks; and it was observed that, as participants made their way through the websites, their ability to use the system improved. ${ }^{(19,34)}$ In order to access the programs, $86 \%(14 / 24)$ of the programs required a log-in from caregivers; it is unclear if log-in requirements hindered usability. ${ }^{14,21,23,26,29,31,32,34,37,38,40,42,43,45)}$ Overall qualitative feedback on user experience, satisfaction, technology acceptance, and usability was positive. ${ }^{(12,18,19,30,31,34-36,40,43,45)}$ Some interventions reported lower acceptance from caregivers, and factors that affected usability such as ethno-cultural linguistics. ${ }^{(20,26,28)}$

\section{Attrition in Interventions for Caregivers}

Rates of attrition were noted to be high in several studies, ranging from $20 \%$ to $62 \%^{(14,23,24,27,28,37)}$ Reasons noted for caregiver attrition included: interventions did not meet their needs, lack of time or energy, perceived uselessness of the application, the caregiver's declining health, or the death or nursing home placement of the care recipient. (23,24,27,28,37) $^{2}$

\section{The Importance of Stage-Specific Information}

Caregivers who evaluated PIB emphasized the need to have stage-specific information readily available, as opposed to information tailored simply to coping with the disease and to destigmatizing topics. ${ }^{(12)}$ Caregivers in Tele-Savvy needed information more applicable to their current situation, whether it was early- or late-stage dementia, as did Mastery over Dementia. ${ }^{(24,41)}$ The DemDisc intervention addresses the need for stage-specific information by providing specific questions, which leads the caregivers to material relevant to their needs. (30) Similarly, Caregiver's Friend features a survey which assesses the needs and stage of the caregiver or PwD and, in turn, directs the user to the relevant material on the site. ${ }^{(25)}$

\section{Featured Material and Use of Vignettes}

The preference for understandable 'bite-sized chunks' of information was highlighted in the study of the Living and Dying Well with Dementia mobile app; participants were less likely to be intimidated by the amount or difficulty of the content that was delivered. ${ }^{(35)}$ Participants who interacted with CARES appreciated both the layout and complex delivery aspects of the content and the use of vignettes, which create a lifelike comparison and personal connection to the material. ${ }^{(27,31)}$ Vignettes were well-received by caregivers in Tele-Savvy, but there was a need for information and videos to portray more complex situations rather than best-case scenarios. ${ }^{(41)}$

\section{Online Flexibility and Forums}

The purpose of many of the caregiver educational programs was to provide an accessible set of information for caregivers. Some interventions featured live forums or 'ask the expert' where a health-care professional led sessions and caregivers could connect according to their availability. ${ }^{(16,17,31,36)}$ Low and high engagement in forums and discussion posts were reported in some interventions. ${ }^{(16,17,24,37,38)}$ These digital community forums were important to caregivers as they are a way of communicating with likeminded peers. ${ }^{(18,36,37)}$

\section{DISCUSSION}

\section{Overview of Findings}

This review identified 24 online educational programs aimed at caregivers of PwD. The programs themselves were varied in the included components, development approaches, and outcomes measured. The studies suggest that online caregiver education modules may benefit caregivers with respect to self-efficacy, anxiety, depression, goal setting, and dementia knowledge; however, more robust RCTs with larger 


\section{SZTRAMKO/LEVINSON: ONLINE EDUCATIONAL TOOLS FOR DEMENTIA CAREGIVERS}

participant numbers are encouraged to confirm the benefits in interventions for caregivers of PwD for the outcomes of dementia knowledge, goal setting, competence and mastery, relationship strain, stress, and quality of life that our review identified. A recent systematic review found that internetbased supportive interventions are effective in improving self-efficacy, depressive symptoms, and stress, but the effects on burden, caregiver reaction to behavioural symptoms, and coping competence were not significant. ${ }^{(4)}$

Although there are differences in outcome measurements or definitions across studies that reduce the consistency of the study designs (for instance, using self-efficacy or competence to describe a similar construct), an important consideration is the interconnectedness of the phenomena measured in these studies. This means that each outcome may influence the other, and it is difficult to gauge what mechanism of change (element of the intervention) is affecting each construct or outcome. For instance, levels of self-efficacy for dementia-related tasks influence depression and burden in caregivers. ${ }^{(8,61)}$ Moreover, our review found that the frequency of use, user engagement, technology acceptability, and quality of the design of the tool varied across interventions. This variation may affect the level of knowledge gained, which may influence feelings of self-efficacy, in turn affecting depressive symptoms and other outcomes relevant to caregivers. The variation in the measurement or description of these outcomes is understandable given the interconnected nature of capabilities and emotions in informal caregiving; this can make it difficult to compare programs in future studies. ${ }^{(62)}$ Understanding the relationship between outcomes of cognitive strategies/stress appraisal, caregiver adjustment, social support, and physiological health will help to contribute to the growing area of caregiver research, and with the development of educational interventions with relevant and impactful material. ${ }^{(63)}$

Knowledge transfer is the most proximal effect of educational interventions; it shapes the beliefs and attitudes toward PwD of caregivers, and may reduce self-blame by the caregiver because they understand what they can, or cannot, control in their interactions. They may also come to understand that many responsive behaviours are secondary to an unmet need of the PwD, and not a result of personal choice. Such beliefs and attitudes may improve goal-setting, mastery, and self-efficacy - all of which improved in some of the included studies. $^{(12,14,25,32)}$ A limitation with many of the included articles is that they did not use validated knowledge assessment tools. Ideally, psychometrically reliable and valid tools, such as the Dementia Knowledge Assessment Scale, ${ }^{(64)}$ should be used to assess knowledge outcomes in caregiver education trials. It is recommended that future studies use a validated tool to reliably measure caregiver knowledge and assess how the outcomes noted above interface with one another.

\section{Program Features and Design Approaches}

This review found that caregiver-knowledge needs are very different, and are dependent on the stage of illness and type of dementia experienced by the PwD. The caregivers in this review appreciated specific and caregiver-relevant information, and we recommend that interventions should provide evidence-based, stage- and problem-specific support across the caregiver journey in order to maximize the diversity, complexity, and applicability of the caregiving scenarios represented. ${ }^{(41,65)}$ There is a recognition that the caregiver journey changes and requires the caregiver to adapt to new caregiving challenges over time as the illness evolves in the PwD. ${ }^{(21)}$ The program features found in this study (see Appendix 2) are consistent with the psychosocial strategies that care navigators provide to family caregivers, including emotional, informational, and instrumental support, which help build self-efficacy. ${ }^{(66)}$

Online educational interventions that are personalized to the needs of the caregiver, as well as to the stage of the $\mathrm{PwD}$, are seldom available. ${ }^{(39)}$ When designing, developing, and implementing online educational interventions, testing for meaningful use among one's target audience is critical, as recognizing the barriers to meaningful use may help to minimize the high attrition rates noted in these studies. Small participant sizes of three to five participants are generally sufficient for such usability testing. ${ }^{(67)}$ For optimal intervention learning to occur, the tool must be consistent and easily accessible, rather than embedded in a larger site; resources that do not require a separate account creation or log-in could potentially reduce barriers to use. We recommend tailoring the online intervention to the caregivers' needs as much as possible, which may include the caregiver receiving information specific to their needs, based on factors unique to the caregiver journey. For example, information presented may be different to the caregiver if the PwD is dealing with a recent diagnosis of dementia, starting treatment, struggling to find supports in the community, coping with responsive behaviours, or wanting to promote brain health.

Most of the interventions included additional components beyond simply educational materials, such as community spaces and online forums, both of which may be helpful to some for coping with caregiver tasks, experience, and the overall journey. Several components in the interventions align with standard principles of multimedia learning. Standard user interface practices include familiar, natural, and logical dialogue; minimalist design for low user cognitive load; easily retrievable information; and error prevention and recognition. ${ }^{\left({ }^{68)}\right.}$ However, not all interventions incorporated best-evidence instructional design for multimedia learning, and evidencebased guidelines have been shown to have a large effect on learning. ${ }^{(69)}$ Incorporating best-evidence approaches in the design of caregiver e-learning is recommended.

Hosting the intervention online is flexible for caregivers, as their schedules are largely consumed by caregiving and they may not have time to attend in-person learning sessions (travel and in-person time). Some interventions feature live forums or 'ask the expert', where a health-care professional will lead and disseminate sessions. A spirit of camaraderie allows caregivers to bond with and support one another through relatable experiences, and may help to support caregiver wellness by 


\section{SZTRAMKO/LEVINSON: ONLINE EDUCATIONAL TOOLS FOR DEMENTIA CAREGIVERS}

reducing their susceptibility to social isolation and loneliness. (36,37) However, synchronous/real-time online interventions may not be convenient or accessible for all caregivers. It is therefore recommended that expert live forums be archived so caregivers can review them at a time that is convenient for them; this recording should feature the experts or session leaders only, to respect the privacy of fellow caregivers.

\section{Strengths and Limitations}

This scoping review structurally mapped and summarized the findings of educational interventions for caregivers of PwD by identifying key themes in outcomes and processes in the literature. Our review bridges important caregiver outcomes with relevant intervention development processes and qualitative caregiver feedback that researchers and policymakers can consider when developing or evaluating online educational tools in RCTs. Despite the thorough methods used in each study, many failed to report confidence intervals in their articles. Only 15/33 articles were RCTs or pre/post studies, and all but one included RCT were unblinded, which introduces a large amount of bias and brings into question the validity of results. The reporting and methodological quality of internet-based health education research has been suboptimal, particularly with the overestimation of effect size, but has increased in quality over time. ${ }^{(70)}$ The remainder of the studies were observational. We therefore believe a major limitation of this review is the low-quality of included studies; we did not critically appraise each source for methodological quality. Included studies did not report on user engagement during design or the design principles they used in developing their content. In addition, the studies did not measure whether the online community forums contributed to outcomes. The content of the tools may have also been altered or removed after the articles were published. This scoping review was not registered before the search was conducted in March 2018; a supplemental literature search was conducted in PubMed for articles up to July 2020, but our search strategy may have missed some more recent publications.

\section{CONCLUSION}

Overall, the 24 respective interventions reported in 33 articles have been designed to respond to the dynamic educational needs of caregivers of PwD. This topic is important because caregivers will keep searching for dementia education and information online as the prevalence of dementia continues to increase. Per the findings of this review, multimedia tools/ online interventions for caregivers of PwD can improve caregiver outcomes, such as self-efficacy, anxiety, and depression, but larger and more robust studies are required with a particular focus on how knowledge modifies and intersects with the other outcomes of relationship strain, burden, stress, mastery, goal setting, and quality of life. Future multi-component interventions may be informed by the measures and practices of knowledge transfer identified in this study, including stagespecific information, vignettes, online forums, and usability.
Future directions for research should investigate the effects of caregiver educational tools on delaying relocation to longterm care homes or reducing hospitalizations for PwD.

\section{ACKNOWLEDGEMENTS}

Richard Sztramko and Anthony J. Levinson are co-first authors. All the authors contributed to the conception and design of the study, and to the analysis, interpretation, and drafting and preparing the manuscript for submission. Anthony J. Levinson receives support through the John R. Evans Chair in Health Sciences Educational Research and Instructional Development.

\section{CONFLICT OF INTEREST DISCLOSURES}

The authors declare that no conflicts of interest exist.

\section{REFERENCES}

1. Alzheimer Society of Canada. Dementia numbers in Canada. Toronto, ON: The Society; 2019. Available from: https:// alzheimer.ca/en/about-dementia/what-dementia/dementianumbers-canada

2. Ringer TJ, Wong-Pack M, Miller P, et al. Understanding the educational and support needs of informal care-givers of people with dementia attending an outpatient geriatric assessment clinic. Ageing Soc. 2020;40(1):205-28.

3. Bressan V, Visintini C, Palese A. What do family caregivers of people with dementia need? A mixed-method systematic review. Health Soc Care Community. 2020;28(6):1942-60.

4. Leng M, Zhao Y, Xiao H, et al. Internet-based supportive interventions for family caregivers of people with dementia: systematic review and meta-analysis. J Med Internet Res. 2020; 22(9):e19468.

5. Teahan Á, Lafferty A, McAuliffe E, et al. Psychosocial interventions for family carers of people with dementia: a systematic review and meta-analysis. J Aging Health. 2020;32(9):1198-213.

6. Hopwood J, Walker N, McDonagh L, et al. Internet-based interventions aimed at supporting family caregivers of people with dementia: Systematic review. JMed Internet Res. 2018;20(6):9548.

7. Zhao Y, Feng $\mathrm{H}, \mathrm{Hu} \mathrm{M}$, et al. Web-based interventions to improve mental health in home caregivers of people with dementia: meta-analysis. J Med Internet Res. 2019;21(5):e13415

8. Williams F, Moghaddam N, Ramsden S, et al. Interventions for reducing levels of burden amongst informal carers of persons with dementia in the community. A systematic review and metaanalysis of randomised controlled trials. Aging Ment Health. 2019;23(12):1629-42.

9. Deeken F, Rezo A, Hinz M, et al. Evaluation of technologybased interventions for informal caregivers of patients with dementia - a meta-analysis of randomized controlled trials. Am J Geriatr Psychiatry. 2019;27(4):426-45.

10. Etxeberria I, Salaberria K, Gorostiaga A. Online support for family caregivers of people with dementia: a systematic review and meta-analysis of RCTs and quasi-experimental studies. Aging Ment Health. 2020;25(7):1165-80.

11. Arksey H, O'Malley L. Scoping studies: towards a methodological framework. Int J Soc Res Methodol. 2005;8(1):19-32.

12. Boots LM, de Vugt ME, Withagen HE, et al. Development and initial evaluation of the web-based self-management program 


\section{SZTRAMKO/LEVINSON: ONLINE EDUCATIONAL TOOLS FOR DEMENTIA CAREGIVERS}

"partner in balance" for family caregivers of people with early stage dementia: An exploratory mixed-methods study. JMIR Res Protoc. 2016;5(1):e33.

13. Boots LM, de Vugt ME, van Knippenberg RJM, et al. A systematic review of internet-based supportive interventions for caregivers of patients with dementia. Int J Geriatr Psychiatry. 2014; 29(4):331-44.

14. Boots LM, de Vugt ME, Kempen GI, et al. Effectiveness of a blended care self-management program for caregivers of people with early-stage dementia (partner in balance): randomized controlled trial. J Med Internet Res. 2018;20(7):e10017.

15. Bass $\mathrm{D}, \mathrm{McClendon} \mathrm{M}$, Brennan $\mathrm{P}$, et al. The buffering effect of a computer support network on caregiver strain. J Aging Health. 1998;10(1):20-43.

16. Brennan PF, Moore SM, Smyth KA. Alzheimer's disease caregivers' uses of a computer network. West J Nurs Res. 1992; 14(5):662-73.

17. Brennan PF. Computer networks promote caregiving collaboration: the ComputerLink Project. In: American Medical Informatics Association's Proceedings of the Annual Symposium on Computer Application in Medical Care 1992. Bethesda, MA: AMIA; 1992. p.156-60.

18. Brennan PF, Smyth K. Elders' attitudes and behavior regarding ComputerLink. In: American Medical Informatics Association's Proceedings of the Annual Symposium on Computer Application in Medical Care 1994. Bethesda, MA: AMIA; 1994. p. 1011.

19. Chiu T, Lottridge D, Development and iterative refinement of an internet-based service for Chinese family caregivers of people with Alzheimer disease. AMIA Annu Symp Proc. 2005:919.

20. Chiu TM, Eysenbach G. Stages of use: consideration, initiation, utilization, and outcomes of an internet-mediated intervention. BMC Med Inform Decis. 2010;10(1):73.

21. Chiu TML, Eysenbach G. Theorizing the health service usage behavior of family caregivers: A qualitative study of an internetbased intervention. Int J Med Inform. 2011;80(11):754-64.

22. Chiu T, Marziali E, Colantonio A, et al. Internet-based caregiver support for Chinese Canadians taking care of a family member with Alzheimer disease and related dementia. Can J Aging. 2009; 28(4):323-36.

23. Blom MM, Zarit SH, Groot Zwaaftink RBM, et al. Effectiveness of an internet intervention for family caregivers of people with dementia: results of a randomized controlled trial. PLoS One. 2015;10(2):e0116622.

24. Pot AM, Blom MM, Willemse BM. Acceptability of a guided self-help internet intervention for family caregivers: mastery over dementia. Int Psychogeriatr. 2015;27(8):1343-54.

25. Beauchamp N, Blair A, Seeley J. Worksite-based internet multimedia program for family caregivers of persons with dementia. Gerontologist. 2005;45(6):793-801

26. Cristancho-Lacroix V, Wrobel J, Cantegreil-Kallen I, et al. A web-based psychoeducational program for informal caregivers of patients with Alzheimer's disease: a pilot randomized controlled trial. J Med Internet Res. 2015;17(5):e117

27. Kajiyama B, Thompson LW, Eto-Iwase T, et al. Exploring the effectiveness of an Internet-based program for reducing caregiver distress using the iCare Stress Management e-Training Program. Aging Ment Health. 2013;17(5):544-54.

28. Núñez-Naveira L, Alonso-Búa B, de Labra $\mathrm{C}$, et al. UnderstAID, an ICT platform to help informal caregivers of people with dementia: a pilot randomized controlled study. BioMed Res Int. 2016;2016:5726465.
29. Pagán-Ortiz ME, Cortés DE, Rudloff N, et al. Use of an online community to provide support to caregivers of people with dementia. J Gerontol Soc Work. 2014;57(6-7):694-709.

30. van der Roest HG, Meiland FJM, Jonker C, et al. User evaluation of the Dementia-specific Digital Interactive Social Chart (DEM-DISC). A pilot study among informal carers on its impact, user friendliness and usefulness. Aging Ment Health. 2010; 14(4):461-70.

31. Gaugler JE, Hobday JV, Robbins JC, et al. CARES ${ }^{\circledR}$ dementia care for families ${ }^{\mathrm{TM}}$ : effects of online, psychoeducational training on knowledge of person-centered care and satisfaction. $J$ Gerontol Nurs. 2015;41(10):18-24.

32. Pleasant ML, Molinari V, Hobday JV, et al. An evaluation of the CARES $®$ Dementia Basics Program among caregivers. Int Psychogeriatr. 2017;29(1):45-56.

33. Lai CKY, Wong LF, Liu K-H, et al. Online and onsite training for family caregivers of people with dementia: results from a pilot study. Int J Geriatr Psychiatry. 2013;28(1):107-08.

34. Boyd K, Nugent C, Donnelly M, et al. An investigation into the usability of the STAR training and re-skilling website for carers of persons with dementia. In: $201436^{\text {th }}$ Annual IEEE Conference Proceedings. IEEE Eng Med Biol Soc. 2014;2014: 4139-42.

35. Bhattacharyya S, Benbow SM, Collins E. Mobile app: living and dying well with dementia. Prog Neurol Psychiatry. 2017; 21(3):4-5.

36. Glueckauf RL, Loomis JS. Alzheimer's Caregiver Support Online: lessons learned, initial findings and future directions. NeuroRehabilitation. 2003;18(2):135-46.

37. Goldberg LR, Bell E, King C, et al. Relationship between participants' level of education and engagement in their completion of the Understanding Dementia Massive Open Online Course. BMC Med Educ. 2015;15(1):60.

38. Chang BL. Internet intervention for community elders. West $J$ Nurs Res. 2004;26(4):461-66.

39. Hales SA, Fossey J. Caring For Me and You: the co-production of a computerised cognitive behavioural therapy (cCBT) package for carers of people with dementia. Aging Ment Health. 2018;22(10):1287-94.

40. Hattink B, Droes R-M, Sikkes S, et al. Evaluation of the Digital Alzheimer Center: testing usability and usefulness of an online portal for patients with dementia and their carers. JMIR Res Protoc. 2016;5(3):e5040.

41. Kovaleva M, Blevins L, Griffiths PC, et al. An online program for caregivers of persons living with dementia: lessons learned. J Appl Gerontol. 2019;38(2):159-82.

42. Bricoli B. NICHE develops patient + family app. Geriatr Nurs. 2015;36(3):249.

43. Verway R, van Berlo M, Duymelinck S, et al. Development of an online platform to support the network of caregivers of people with dementia. Stud Health Technol Inform. 2016;225:567-71.

44. Griffiths PC, Kovaleva M, Higgins M, et al. Tele-Savvy: an online program for dementia caregivers. Am J Alzheimers Dis Other Demen. 2018;33(5):269-76.

45. Metcalfe A, Jones B, Mayer J, et al. Online information and support for carers of people with young-onset dementia: a multisite randomised controlled pilot study. Int J Geriatr Psychiatry. 2019;34(10):1455-64.

46. Steffen AM, McKibbin C, Zeiss AM, et al. The revised scale for caregiving self-efficacy: reliability and validity studies. J Gerontol B Psycho Sci Soc Sci. 2002;57(1):P74-P86. 


\section{SZTRAMKO/LEVINSON: ONLINE EDUCATIONAL TOOLS FOR DEMENTIA CAREGIVERS}

47. Bedard M, Molloy DW, Squire L, Dubois S, Lever JA, O'Donnell M. The Zarit Burden Interview: a new short version and screening version. Gerontologist. 2001;41(5):652-657.

48. Radloff SS. The CES-D scale: a self-report depression scale for research in the general population. Appl Psychol Meas. 1977; 1(3):385-401.

49. Beck A, Steer R, Brown G. Manual for the Beck Depression Inventory-II. San Antonio, TX: Psychological Corporation; 1996.

50. Zigmond AS, Snaith RP. The hospital anxiety and depression scale. Acta Psychiatr Scand. 1983;67(6):361-70.

51. Spielberger C, Gorsuch R, Lushene R. Manual for the State-Trait Anxiety Inventory. Palo Alto, CA: Consulting Psychologists Press; 1970.

52. Derogatis LR, Melisaratos N. The Brief Symptom Inventory: an introductory report. Psychol Med. 1983;13(3):595-605.

53. WHO. The World Health Organization quality of life assessment (WHOQOL): development and general psychometric properties. Soc Sci Med. 1998;46(12):1569-85.

54. Coast J, Flynn T, Sutton E, et al. Investigating Choice Experiments for Preferences of Older People (ICEPOP): evaluative spaces in health economics. J Health Serv Res Policy. 2008;13(Suppl 3):31-37.

55. Patrick DL, Danis M, Southerland LI, et al. Quality of life following intensive care. J Gen Intern Med. 1988;3(3):218-23.

56. Herdman M, Gudex C, Lloyd A, et al. Development and preliminary testing of the new five-level version of EQ-5D (EQ5D-5L). Qual Life Res. 2011;20(10):1727-36.

57. Kiresuk TJ, Sherman RE. Goal attainment scaling: a general method for evaluating comprehensive community mental health programs. Community Ment Health J. 1968;4(6):443-53.

58. Pearlin LI, Mullan JT, Semple SJ, et al. Caregiving and the stress process: an overview of concepts and their measures. Gerontologist. 1990;30(5):583-94.

59. Schepers AK, Orrell M, Shanahan N, et al. Sense of competence in dementia care staff (SCIDS) scale: development, reliability, and validity. Int Psychogeriatr. 2012;24(7):1153-62.

60. Lazarus RS, Folkman S. Stress, appraisal, and coping. New York: Springer; 1984.
61. Gallagher D, Ni Mhaolain A, Crosby L, et al. Self-efficacy for managing dementia may protect against burden and depression in Alzheimer's caregivers. Aging Ment Health. 2011;15(6): 663-70.

62. Horrell B, Stephens C, Breheny M. Capability to care: supporting the health of informal caregivers for older people. Health Psychol. 2015;34(4):339-48.

63. Hawken T, Turner-Cobb J, Barnett J. Coping and adjustment in caregivers: a systematic review. Health Psychol Open. 2018;5(2):2055102918810659.

64. Annear MJ, Toye CM, Eccleston CE, et al. Dementia Knowledge Assessment Scale: sevelopment and preliminary psychometric properties. J Am Geriatr Soc. 2015;63(11):2375-81.

65. Wasilewski MB, Stinson JN, Cameron JI. Web-based health interventions for family caregivers of elderly individuals: a scoping review. Int J Med Inform. 2017;103:109-38.

66. Merrilees JJ, Bernstein A, Dulaney S, et al. The Care Ecosystem: promoting self-efficacy among dementia family caregivers. Dementia. 2020;19(6):1955-73.

67. Nielsen J. Why you only need to test with 5 users. Fremont, CA: Nielsen Norman Group; 2000. Available from: https://www. nngroup.com/articles/why-you-only-need-to-test-with-5-users/

68. Nielsen J. 10 usability heuristics for user interface design. Fremont, CA: Nielsen Norman Group; 1994. Available from: https://www.nngroup.com/articles/ten-usability-heuristics/

69. Clark RC, Mayer RE. E-learning and the science of instruction: proven guidelines for consumers and designers of multimedia learning, $4^{\text {th }}$ edition. Hoboken, NJ: John Wiley \& Sons; 2016.

70. Cook DA, Levinson AJ, Garside S. Method and reporting quality in health professions education research: a systematic review. Med Educ. 2011;45(3):227-38.

Correspondence to: Cynthia Lokker, MSc, PhD, Health Information Research Unit, Department of Health Research Methods, Evidence, and Impact, McMaster University, CRL 125, 1280 Main St W., Hamilton, ON L8S 4K1

E-mail: lokkerc@mcmaster.ca 


\section{APPENDIX A. \\ Search strategy key words, MeSH terms and combinations employed to identify the studies that were used}

MEDLINE Search Terms

((dementia (MeSH) OR dementia (keyword) OR Alzheimer (keyword))

AND (Caregiv* (MeSH), carer* (MeSH), Caregivers (keyword)) AND (Telemedicine (MeSH) OR eHealth (keyword) OR Telemedicine (keyword) OR Internet (MeSH) OR Computer Communication Networks (MeSH) OR Programmed Instruction as Topic (MeSH) OR Software (MeSH) OR internet (keyword) OR eLearn* (keyword) OR module (keyword) OR online intervention* (keyword) OR mobile app* (keyword))

((dementia (MeSH) AND dementia (keyword) OR Alzheimer (keyword))

AND (Caregiv* (MeSH), carer* (MeSH), Caregivers (keyword)) AND (Telemedicine (MeSH) OR eHealth (keyword) OR Telemedicine (keyword) OR Internet (MeSH) OR Computer Communication Networks (MeSH) OR Programmed Instruction as Topic (MeSH) OR Software (MeSH) OR internet (keyword) OR eLearn* (keyword) OR module (keyword) OR online intervention* (keyword) OR mobile app* (keyword))

\section{PubMed Search Terms}

$1 \quad((($ dementia OR dementia OR Alzheimer*)) AND (caregivers OR caregiv* OR carer*)) AND (Telemedicine OR internet OR Computer Communication Networks OR software OR internet OR elearn OR module OR online intervention OR mobile app OR mobile application)

\section{CINAHL Search Terms}

(“dementia OR Alzheimer*” OR (MH "Dementia+")) AND (((MH “Caregiver Burden”)) OR ("caregiver OR carer*”)) AND ("telemedicine" OR ("ehealth or e-health or telecare or telemedicine or telehealth") OR ((MH "Internet")) OR ((MH "Computer Communication Networks")) OR ((MH “Software”)) OR "software" OR “elearn*” OR "module*” OR ("online intervention") OR ("mobile app*") OR ("mobile application") OR ((MH “Telehealth+") OR “ehealth"))

EMBASE Search Terms

1 MEDLINE: dementia (MeSH) OR dementia (keyword) OR Alzheimer (keyword)

2 Caregiv* (MeSH), carer* (MeSH), Caregivers (keyword)

3 Telemedicine (MeSH) OR eHealth (keyword) OR Telemedicine (keyword) OR Internet (MeSH) OR Computer Communication Networks (MeSH) OR Programmed Instruction as Topic (MeSH) OR Software (MeSH) OR internet (keyword) OR eLearn* (keyword) OR module (keyword) OR online intervention* (keyword) OR mobile app* (keyword)

$6 \quad 1$ AND 2 AND 3 


\section{APPENDIX B. Characteristics of included studies}

\begin{tabular}{|c|c|c|c|}
\hline Intervention & Study type & Study details & General results \\
\hline \multirow[t]{2}{*}{$\begin{array}{l}\text { Partner in Balance } \\
(\mathrm{PIB})\end{array}$} & $\begin{array}{l}\text { Mixed } \\
\text { Methods }^{(12)}\end{array}$ & $\begin{array}{l}\text { Focus groups with CGs, individual } \\
\text { interviews with healthcare } \\
\text { professionals, usability tests with } \\
\text { caregivers and professionals, and an } \\
\text { initial pilot with caregivers. }(\mathrm{n}=28)\end{array}$ & $\begin{array}{l}\text { CGs appreciated completing the intervention at } \\
\text { home. The content and guided sessions was perceived } \\
\text { positively. Preliminary effects of self-efficacy and goal } \\
\text { attainment were positive; significance not reported. }\end{array}$ \\
\hline & $\mathrm{RCT}^{(14)}$ & $\begin{array}{l}\text { PIB intervention vs. wait-list control } \\
\text { group. }(\mathrm{n}=81)\end{array}$ & $\begin{array}{l}\text { PIB increased the self-efficacy, quality of life, and } \\
\text { mastery in CGs. } \\
\text { No differences were found in depression, anxiety, } \\
\text { or stress. }\end{array}$ \\
\hline \multirow[t]{4}{*}{$\begin{array}{l}\text { ComputerLink } \\
\text { (CL) }\end{array}$} & $\mathrm{RCT}^{(15)}$ & $\begin{array}{l}\text { Measured effect of CL on strain } \\
\text { between the experimental group } \\
(\mathrm{n}=51) \text { and control group }(\mathrm{n}=51) \text {, } \\
\text { who did not have access to CL. }\end{array}$ & $\begin{array}{l}\text { CL reduced relationship-related strain in the } \\
\text { experimental group vs. control group; not statistically } \\
\text { significant. }\end{array}$ \\
\hline & $\mathrm{RCT}^{(17)}$ & $\begin{array}{l}\text { Experimental group }(\mathrm{n}=51) \text { had } \\
\text { access to CL for } 12 \text { months to } \\
\text { evaluate interaction. The control } \\
\text { group was assigned to a telephone- } \\
\text { only intervention }(\mathrm{n}=51) \text {. }\end{array}$ & $\begin{array}{l}\text { CGs accessed CL } 3888 \text { times. Behavioral indicators } \\
\text { showed that CL promoted collaboration between CGs. } \\
\text { CGs sought info over } 500 \text { times and spent an average } \\
\text { of } 10 \text { minutes upon entry. CGs posted } 749 \text { messages } \\
\text { on the forum. }\end{array}$ \\
\hline & Observational $^{(16)}$ & $\begin{array}{l}\text { CL terminal modem system was } \\
\text { installed in participating homes for } \\
1-8 \text { months, } 1 \text { week of activity was } \\
\text { analyzed }(n=47) \text {. }\end{array}$ & $\begin{array}{l}\text { CL was accessed } 98 \text { times by } 29 \text { participants, Mean of } \\
2 \text { log-ins, range } 0-13 \text {. Most frequently accessed was } \\
\text { the forum ( } 80 \text { time), and the private mail ( } 56 \text { times). }\end{array}$ \\
\hline & Observational $^{(18)}$ & $\begin{array}{l}\text { Attitudes towards CL was measured } \\
\text { with a researcher- developed self- } \\
\text { administered } 20 \text {-item survey }(n=35) \text {. }\end{array}$ & $\begin{array}{l}75 \% \text { interested, } 36 \% \text { distressed; } 29 \% \text { excited, } 26 \% \\
\text { afraid. Overall, CGs perceived intervention as } \\
\text { positive. }\end{array}$ \\
\hline \multirow[t]{4}{*}{$\begin{array}{l}\text { Internet-Based } \\
\text { Support Services } \\
\text { (ICSS) }\end{array}$} & $\begin{array}{l}\text { Observational, } \\
\text { usability }^{(19)}\end{array}$ & $\begin{array}{l}\text { Bilingual Chinese CGs participated in } \\
\text { a think-a-loud usability study while } \\
\text { they navigated the site }(n=3) \text {. }\end{array}$ & $\begin{array}{l}\text { The interface was perceived as functional and the } \\
\text { large icons on the email prompted participants } \\
\text { appropriately. The text and site design provided } \\
\text { context to facilitate use. }\end{array}$ \\
\hline & Qualitative $^{(21)}$ & $\begin{array}{l}\text { Interviews explored CGs attitudes } \\
(\mathrm{n}=14) \text {. }\end{array}$ & $\begin{array}{l}\text { A needs factor must be present for use; needs of } \\
\text { CGs must change over time as does their use; CGs } \\
\text { are desperate for information as there is so much } \\
\text { information out there and they do not know which/ } \\
\text { who to trust. }\end{array}$ \\
\hline & $\begin{array}{l}\text { Mixed } \\
\text { Methods }\end{array}$ & $\begin{array}{l}\text { Multi-phased, longitudinal } \\
\text { observation }(n=46)\end{array}$ & $\begin{array}{l}\text { Regular engagement with the intervention was } \\
\text { associated with reduction in CG burden, post- } \\
\text { intervention. Cultural beliefs shaped CG needs } \\
\text { and ethno-cultural-linguistics had effect on system } \\
\text { usability and were associated with use. }\end{array}$ \\
\hline & $\begin{array}{l}\text { Mixed } \\
\text { Methods }^{(22)}\end{array}$ & $\begin{array}{l}\text { Surveys and interviews explored } \\
\text { Chinese-CGs use of ICSS, and the } \\
\text { effects on the CG health outcomes } \\
(n=28) \text {. }\end{array}$ & $\begin{array}{l}\text { CGs who had higher scores started the service earlier } \\
\text { than those with lower scores. Nonusers had increased } \\
\text { perceived burden; occasional users had minimal } \\
\text { changes, and frequent users had a decrease in scores. }\end{array}$ \\
\hline \multirow[t]{2}{*}{$\begin{array}{l}\text { Mastery Over } \\
\text { Dementia (MoD) }\end{array}$} & Qualitative $^{(24)}$ & $\begin{array}{l}\text { Feasibility, comprehensibility and } \\
\text { usefulness of MoD in the MoD group } \\
\text { of the trial }(n=149) \text {. }\end{array}$ & $\begin{array}{l}68 \text { CGs completed all lessons within } 6 \text { months, } 81 \text { did } \\
\text { not finish all. } 6 \text { did not start. Those who did not finish } \\
\text { reported the material was not relevant/faced too much } \\
\text { CG burden. }\end{array}$ \\
\hline & $\mathrm{RCT}^{(23)}$ & $\begin{array}{l}\text { CGs completed surveys at baseline, } \\
\text { during, and after the } 6 \text {-month pilot } \\
\text { to evaluate effectiveness of the } \\
\text { intervention Experimental group } \\
n=251 \text {; control group } n=96 \text {. }\end{array}$ & $\begin{array}{l}\text { CGs in the experimental group showed significant } \\
\text { reduction in the two outcomes of anxiety and } \\
\text { depression. }\end{array}$ \\
\hline
\end{tabular}




\section{APPENDIX B. Continued}

\begin{tabular}{|c|c|c|c|}
\hline Intervention & Study type & Study details & General results \\
\hline $\begin{array}{l}\text { Caregiver's } \\
\text { Friend: Dealing } \\
\text { with Dementia }\end{array}$ & $\mathrm{RCT}^{(25)}$ & $\begin{array}{l}\text { Family CGs (also employed outside } \\
\text { of the home) completed surveys } \\
\text { pre-and } 30 \text {-day post-intervention } \\
\text { with a waitlist control condition. } \\
\text { Experimental group } n=150 \text {; control } \\
\text { group } n=149 \text {. }\end{array}$ & $\begin{array}{l}\text { Use of intervention significantly improved CG self- } \\
\text { efficacy and reduced stress, depression, anxiety, and } \\
\text { strain, whilst increasing perception of CG gain and } \\
\text { intention to seek help; the frequency of coping skills } \\
\text { did not change. }\end{array}$ \\
\hline Diapason & $\mathrm{RCT}^{(26)}$ & $\begin{array}{l}\text { Experimental group }(n=25) \text { used } \\
\text { Diapason for } 3 \text { months while control } \\
\text { group }(n=24) \text { proceeded usual care. }\end{array}$ & $\begin{array}{l}\text { CGs in the experimental group significantly improved } \\
\text { their understanding of dementia. Qualitative results } \\
\text { indicated low acceptance from CGs; CGs desire more } \\
\text { dynamic and personalized social interventions. There } \\
\text { were no significant effects in perceived stress, self- } \\
\text { efficacy, burden, depressive symptoms, or perceived } \\
\text { health between groups. }\end{array}$ \\
\hline
\end{tabular}

\begin{tabular}{|c|c|c|}
\hline iCare & $\begin{array}{l}\text { RCT/mixed } \\
\text { methods }^{(27)}\end{array}$ & $\begin{array}{l}\text { CGs completed questionnaires } \\
\text { pre-and-post intervention. The } \\
\text { experimental group }(n=75) \text { interacted } \\
\text { with the iCare intervention for } \\
3 \text { months and the control group } \\
(n=75) \text { had access to an information- } \\
\text { only condition. }\end{array}$ \\
\hline UnderstAID & $\mathrm{RCT}^{(28)}$ & $\begin{array}{l}\text { Experimental group was provided } \\
\text { access to UnderstAID }(n=30) \text {; control } \\
\text { group maintained their usual lifestyle } \\
\text { and practices }(n=31) \text {. }\end{array}$ \\
\hline
\end{tabular}

CGs in the experimental group experienced statistically significant reductions in stress, postintervention; depression, quality of life, and caregiver bother also improved but were not statistically significant. 47 participants withdrew.

The experimental group experienced statistically significant improvement in depressive symptoms but not competence or satisfaction. $33.3 \%$ of CGs were satisfied with the app and 50\% assessed it as technically acceptable; UnderstAID was iterated to suit said suggestions.

\begin{tabular}{|c|c|c|}
\hline Cuidate Cuidador & $\mathrm{RCT}^{(29)}$ & $\begin{array}{l}\text { Quasi-experimental 2-group design } \\
\text { with pre- and post-intervention } \\
\text { assessment. CGs }(\mathrm{n}=23 \text { ) were } \\
\text { given 1-hour to review the usability } \\
\text { and usefulness of intervention. } \\
\text { Improvements were made to the } \\
\text { intervention per feedback. Following, } \\
\text { participants were assigned to a control } \\
\text { ( } \mathrm{n}=23 \text { ) or experimental group ( } \mathrm{n}=17 \text { ) } \\
\text { to test the intervention effectiveness. }\end{array}$ \\
\hline $\begin{array}{l}\text { DEMentia-specific } \\
\text { Digital Interactive } \\
\text { Social Chart } \\
\text { (DEM-DISC) }\end{array}$ & $\mathrm{RCT}^{(30)}$ & $\begin{array}{l}\text { Experimental group ( } \mathrm{n}=14 \text { CGs and } \\
12 \text { PwD) were given DEM-DISC for } \\
\text { two months. Control group ( } \mathrm{n}=14 \\
\text { CGs and } 11 \text { PwD) relied on their } \\
\text { typical information sources. }\end{array}$ \\
\hline
\end{tabular}

$\begin{array}{lll}\begin{array}{l}\text { Cares for Families } \\ \text { (CARES) }\end{array} & \text { Pre-post pilot }{ }^{(32)} & \begin{array}{l}\text { Outcome measures were assessed } \\ \text { at baseline, post intervention, and } \\ \text { after } 30 \text { days of the intervention of } \\ \text { CARES (n=51). }\end{array} \\ \text { CARES Dementia } & \text { Pre-post pilot }{ }^{(31)} & \begin{array}{l}\text { Assess improvement in dementia } \\ \text { knowledge. Descriptive qualitative } \\ \text { and quantitative data was sought } \\ \text { through open-ended questions with } \\ \text { 41 CGs. }\end{array}\end{array}$

Post-intervention, the experimental group reported higher self-mastery, lower depressive symptomatology, and greater sense of social support than the control group. However, the intervention group felt a higher sense of CG burden than the control group. Results were not statistically significant although participants valued the intervention.

The participants appreciated usability and usefulness; participants felt the app would be useful for CGs who had little access to education. The participants felt that the app could help prepare CGs for future events. No differences between both groups at posttest were found for self-efficacy, quality of life, and knowledge.

Significant improvement in CG knowledge and components of CG; participants appreciated the vast topics including person-centered care, behaviour modification, and framework.

Knowledge and competence significantly improved post intervention. CGs appreciated the content and flexibility of the online intervention. CGs also appreciated the vignettes. The intervention reportedly provided sufficient and needed information to the CGs. 


\section{APPENDIX B. Continued}

\begin{tabular}{llll}
\hline Intervention & Study type & Study details & General results \\
\hline Ginko & Pre-post pilot ${ }^{(33)}$ & $\begin{array}{l}\text { CGs attended a 7-week face to face } \\
\text { workshop to examine Ginko's impact } \\
\text { of CG-knowledge of dementia and } \\
\text { joined the forum thereafter (N=8); or } \\
\text { took the courses online (N=3). }\end{array}$ & $\begin{array}{l}\text { Knowledge gained by the online workshop } \\
\text { participants after attending the workshop was } \\
\text { significantly greater than that gained by onsite } \\
\text { workshop only participants. Only the onsite } \\
\text { participants' quality of life and anxiety and depression } \\
\text { reduced significantly after the workshop. }\end{array}$ \\
$\begin{array}{llll}\text { STAR Training } \\
\text { Program }\end{array}$ & $\begin{array}{l}\text { Observational, } \\
\text { usability }{ }^{(34)}\end{array}$ & $\begin{array}{l}\text { To test usability of STAR as well as } \\
\text { mitigate any user obstacles. Involved } \\
\text { CGs (n=5; } 2 \text { males, 3 females; mean } \\
\text { age=45) CGs of PwD. Participants } \\
\text { were asked to perform the same tasks } \\
\text { on STAR, whilst gaze and heat maps }\end{array}$ & $\begin{array}{l}\text { 60\% of the participants were able to perform half } \\
\text { or more of the tasks; } 80 \% \text { completed the course, } \\
\text { games, and quiz; 0 participants were able to find the } \\
\text { page guide. Task efficiency was also recorded; as the } \\
\text { participant worked their way through the site, they } \\
\text { became more efficient. }\end{array}$
\end{tabular}

Living and Observational, Workshops with CGs were conducted Dying Well with usability ${ }^{(35)}$ Dementia

AlzOnline

Observational $^{(36)}$

\begin{tabular}{|c|c|}
\hline $\begin{array}{l}\text { Massive Open } \\
\text { Online Course } \\
\text { (MOOC): } \\
\text { Understanding } \\
\text { Dementia } \\
\text { (MOOC) }\end{array}$ & Observational $^{(37)}$ \\
\hline $\begin{array}{l}\text { Informative } \\
\text { Website for }\end{array}$ & $\begin{array}{l}\text { Observational, } \\
\text { feasibility }^{(38)}\end{array}$ \\
\hline
\end{tabular}

Caregivers

(name

undisclosed)

$\begin{array}{lll}\begin{array}{l}\text { Caring for Me and } \\ \text { You }\end{array} & \begin{array}{l}\text { Observational, } \\ \text { usability }\end{array} & \begin{array}{l}\text { Consists of three phases: 1) Data } \\ \text { gathering of literature; } 2) \text { co-creation } \\ \text { with } \mathrm{CG} ; 3) \text { testing where }(\mathrm{n}=3) \mathrm{CG} \\ \text { tested the intervention. }\end{array}\end{array}$

Digital Mixed-

Alzheimer's $\quad$ Methods $^{(40)}$

Centre (DAC) to provide an initial evaluation. Sample size and participant details not reported.

3-Phase Evaluation: 1) integration of services as well as development of the lessons and website. $2 \&$

3) evaluation where constructive feedback was gained from their first group of graduates $(n=9)$.

\section{CGs $(n=9500)$ completed} Understanding Dementia MOOC. Information was collected to understand educational background, user demographics, and amount of usage. Completion per background was assessed.

To determine the feasibility of the intervention, CGs $(n=21)$ were given the intervention for 6 months. CG self-reported surveys and feedback.
The participants appreciated usability and usefulness; participants felt the app would be useful for CGs who had little access to education. The participants felt that the app could help prepare CGs for future events.

Feedback alluded to iterating the intervention to be more usable and useful. Home page changes were suggested as CGs desired direct links to the website specs (i.e. direct link to the forum).

A total of 4409 individuals engaged in the discussion forums and made a total of 45,955 discussion posts. Of these, 2896 completed the MOOC. Participants with low education levels (elementary-vocational training) were just as likely to complete the MOOC as educated individuals.

CGs reported they used the site between 2-30 times. Some were able to view the information and could respond to questionnaires. Recommends longitudinal studies be conducted with broader participant populations or varying levels of education. Outcome measures and significance were not reported.

Authors believe the intervention was developed in a way which represents the needs of CGs. Specifically, content, style, and format of delivery compliments best practices of experts. RCT is now underway.

A slight majority of participants enjoyed the layout of the site; all participants felt the material was understandable and clear; ease-of-use with the site was noted. Survey results show 145 reported using the site at least twice; of these 145 , the majority were CGs. Interview responses also indicated regular use; overall response was positive. 
SZTRAMKO/LEVINSON: ONLINE EDUCATIONAL TOOLS FOR DEMENTIA CAREGIVERS

\section{APPENDIX B. Continued}

\begin{tabular}{|c|c|c|c|}
\hline Intervention & Study type & Study details & General results \\
\hline \multirow[t]{2}{*}{ Tele-Savvy } & Qualitative $^{(41)}$ & $\begin{array}{l}\text { To explore the acceptability of the } \\
\text { intervention, CGs were recruited } \\
(\mathrm{n}=46) \text { to test the intervention } \\
\text { of which } 36 \text { completed. Authors } \\
\text { interviewed the } 36 \text { CGs who } \\
\text { completed the intervention via semi- } \\
\text { structured telephone interviews. } \\
\text { Content was thematically analyzed. }\end{array}$ & $\begin{array}{l}\text { Themes: connectedness, distracted participants, } \\
\text { different CG situations, technical difficulties, stage } \\
\text { specific information, CG strategies. Authors conclude } \\
\text { that interventions like Tele-Savvy are feasible for } \\
\text { CG-distant-training. }\end{array}$ \\
\hline & Pre-post ${ }^{(44)}$ & $\begin{array}{l}22 \text { CGs in the first phase and } 42 \text { CGs } \\
\text { in the second phase were recruited } \\
\text { to enroll in the } 6 \text {-week intervention } \\
\text { and complete pre- and post-program } \\
\text { evaluation questionnaires. }\end{array}$ & $\begin{array}{l}57 \text { CGs completed the program and demonstrated } \\
\text { significant improvements in caregiver burden, } \\
\text { competency, depression, and responses to symptoms } \\
\text { of dementia. Higher CG competence post-program } \\
\text { mediated the pre-to-post reductions in burden. }\end{array}$ \\
\hline $\begin{array}{l}\text { Network Support } \\
\text { Dementia Project }\end{array}$ & Qualitative $^{(43)}$ & $\begin{array}{l}\text { Through semi-structured interviews, } \\
\text { informal and formal CGs ( } \mathrm{n}=7 ; 32 \text {, } \\
\text { respectively) participated to gain } \\
\text { insight and first impressions. }\end{array}$ & $\begin{array}{l}\text { Impressions were overall positive; participants felt } \\
\text { the use of the platform would promote cooperation } \\
\text { with other members of the care network, and in turn, } \\
\text { improve the quality and efficiency of care PwD receive. } \\
\text { Informal CGs reportedly used the platform daily while } \\
\text { formal CGs reportedly used the platform weekly. }\end{array}$ \\
\hline $\begin{array}{l}\text { Nurses Improving } \\
\text { Care for Health } \\
\text { System Elders } \\
\text { (NICHE) }\end{array}$ & Descriptive $^{(42)}$ & $\begin{array}{l}\text { Brief description of patient and } \\
\text { family mobile phone application to } \\
\text { support education needs. The app } \\
\text { contains information written in lay } \\
\text { language, covering } 24 \text { CG-centered } \\
\text { topics (e.g. dealing with dementia, } \\
\text { medications, etc.). }\end{array}$ & N/A \\
\hline RHAPSODY & $\begin{array}{l}\text { RCT, } \\
\text { usability }^{(45)}\end{array}$ & $\begin{array}{l}61 \text { CGs ( } \mathrm{n}=30 \text { in experimental } \\
\text { group; } \mathrm{n}=31 \text { in wait list control with } \\
\text { delayed access) in Europe used the } \\
\text { online information and skill-building } \\
\text { website and participated in semi- } \\
\text { structured interviews to assess user } \\
\text { satisfaction, acceptability, and CG } \\
\text { wellbeing. Results were thematically } \\
\text { and descriptively analyzed. }\end{array}$ & $\begin{array}{l}\text { Qualitative feedback on user experience, satisfaction, } \\
\text { and acceptability at week } 6 \text { for the experimental } \\
\text { group and week } 12 \text { for the control group were } \\
\text { positive; the CGs felt that the program was easy to } \\
\text { use and accessible but expressed some content was } \\
\text { not relevant. } 93 \% \text { of CGs rated the program as good, } \\
\text { very good, or excellent. Experimental group CGs } \\
\text { reported lower levels of stress and negative reactions } \\
\text { to symptoms; there were no statistically significant } \\
\text { differences in change scores between groups for self- } \\
\text { efficacy, burden, or quality of life. }\end{array}$ \\
\hline
\end{tabular}




\section{SZTRAMKO/LEVINSON: ONLINE EDUCATIONAL TOOLS FOR DEMENTIA CAREGIVERS}

\section{APPENDIX C. Description of the online educational programs developed for caregivers of persons with dementia.}

1. Partner in Balance (PIB) was developed for caregivers to set goals and evaluate goal attainment and tested through a robustly designed, single-blind RCT. Featured modules focus on acceptance, balancing activities, communication, coping with stress, focusing on the positive, insecurities and remuneration, self-understanding, the changing family member, and social relations and support. ${ }^{(12-14)}$

2. ComputerLink (CL), developed and tested through multiple studies from 1990-1996, was designed for caregivers in the home. CL provides information, communication, and decision support for caregivers. A nurse facilitates discussion forums and answers questions. CL was delivered through a terminal system, which was installed in the caregiver's home. $^{(15-18)}$

3. Internet Based Support Services (ICSS) was created for bilingual Chinese caregivers of PwD. Bilingual caregivers desired online resources in both English and Chinese. The ICSS site consists of email support, 400 pages of dementiaspecific information, and information about English and Chinese community resources. ${ }^{(20-22)}$

4. Mastery Over Dementia $(\mathrm{MoD})$ consists of 8 modules and a booster session facilitated by an experienced psychologist. The purpose of the intervention is to assist with coping strategies, therapeutic techniques, as well as educational knowledge on dementia. ${ }^{(23-24)}$

5. Caregiver's Friend: Dealing with Dementia features an array of text and videos which emphasize positive caregiving strategies and practices. Designed by researchers and experts, the content is personalized, whereby caregivers can fill out a survey which directs them to an area or topic on the site. The site features three modules: Being a Caregiver, Coping with Emotions, and Common Difficulties. ${ }^{(25)}$

6. Diapason is a fully automated site for caregivers. The free tool consists of a platform where CGs can access thematically-organized information. The information is presented throughout a 12-week program, and features the following: caregiver stress, understanding the disease, maintaining autonomy, understanding reactions, coping with troubles, communicating, improving daily life, avoiding fall risks, interventions, social and financial support, the future, and an overall summary. The site also features relaxation videos, stories and testimonials, glossary for terms, and a forum monitored by a psychologist. ${ }^{(26)}$

7. iCare, a collection of modules, presents dementia-based content for caregivers. Each module features actors portraying relevant situations (i.e. caregiver and loved one with dementia). The users are encouraged to finish each module within 7-10 days. ${ }^{(27)}$

8. UnderstAID features 5 modules, focusing on 15 different topics. Module topics consist of cognitive declines (focused on attention, memory, and orientation), daily tasks (focused on bathing, incontinence, massage and touch, and physical exercise), behavioral changes (focused on anxiety and agitation, depression, manic symptoms, emotional control, and recognition), social activities (communication and apathy, and loss of motivation), and the CG (focused on coping with own stress and motivation). ${ }^{(28)}$
9. Cuidate Cuidator, with a name that translates to Caregiver, take care of yourself, is a Spanish site and intervention which features information on dementia, including how to manage dementia-related behaviour, caregiver stories, and self-care. To respond to literacy issues in the area, the information can be accessed in either Spanish or English. ${ }^{(29)}$

10. DEMentia-specific Digital Interactive Social Chart (DEM-DISC), an online intervention which features tailored information on dementia care and services, whereby caregivers can ask questions about dementia, related needs, or services. ${ }^{(30)}$

11. Cares for Families (CARES $($ ) $)$ is an online site featuring information, created by experts and family caregivers. The site features relevant modules which focus on caregiving strategies and dementia knowledge. ${ }^{(31)}$

12. CARES $®$ Dementia Basics presents multiple caregiver scenarios. The intervention consists of four modules, which focus on person-centered care, introductory information on dementia, understanding behaviour as communication, and the CARES approach (connect, assess, respond, evaluate, and share with other team members when providing care). ${ }^{(32)}$

13. Ginko, a dementia-resource website, consists of a 7-week training workshop for caregivers. Upon workshop completion, can join the online community and participate in the forum. ${ }^{(33)}$

14. STAR Training Program (STAR) consist of a site which hosts a training program. The featured modules aim to teach better care techniques, as well as facilitate dementia education. ${ }^{(34)}$

15. Living and Dying Well with Dementia: Mobile App was developed as a free, accessible and easy-to-use resource. The app's mission is to promote understanding about dementia and its key issues during end-of-life care through storytelling. Throughout Jill's Journey, the user experiences Jill aging, the onset of Jill's dementia, as well as Jill dying. As the user embarks on the journey, they can participate in various prompts and exercises. ${ }^{(35)}$

16. AlzOnline is a site which hosts relevant educational modules, live forums with experts, and room for companionship and connecting with other caregivers. AlzOnline is also integrated with a telephone support service. ${ }^{(36)}$

17. Massive Open Online Course: Understanding Dementia (MOOC) is a 9 week, 9-unit online course. The MOOC is designed to support caregivers with limited education. In order to move to the next unit, the user must pass a quiz. There is also a peer-to-peer forum, and an "Ask the Experts" discussion board. ${ }^{(37)}$

18. An Informative Website for caregivers, conceptualized by Chang (2004) consists of four online modules, focusing on cognitive behavioural therapy in relation to caregiving for older adults with dementia. The site also features other links to resources. Although the educational resources in the intervention reportedly lack detail, the testing of the resources was quite robust. ${ }^{(38)}$

19. Caring for Me and You, a computerized cognitive behavioural therapy (cCBT) package, is a standalone intervention, which features an educational arm. The purpose of the intervention is to support caregivers through the dementia journey. ${ }^{(39)}$ 


\section{SZTRAMKO/LEVINSON: ONLINE EDUCATIONAL TOOLS FOR DEMENTIA CAREGIVERS}

20. Digital Alzheimer's Centre (DAC) is a website which offers dementia information, definitions, recent news, as well as community/forum and events sections. Alike similar resources, information is written in lay language. Any user can view the site's home page; however, they are required to sign in to view the entire site. ${ }^{(40)}$

21. Tele-Savvy is an online adaptation of a previous evidencebased, in-person dementia resource. The intervention mimics the in-person course through leveraging vignettebased modules, coupled with video-coaching sessions and offline caregiver-based exercises. The purpose of this psychoeducational resource is to expand users' knowledge, skills, and self-efficacy to overall improve their experience with caregiving. ${ }^{(41,44)}$

22. Network Support Dementia Project aims to connect multiple multimedia resources onto one accessible site. Merging three care organizations which are already used in the region, the purpose was to provide related information about dementia, information exchange between caregivers, as well as between caregivers and healthcare professionals. ${ }^{(43)}$

23. Nurses Improving Care for Health System Elders (NICHE) is a tool designed for nurses to teach caregivers at home. NICHE was created to assist patients and families in the lifecycle of the disease - from diagnosis to death. Informative but not diagnostic, the app is designed to be used by older adults as its text is in lay terms and has an easy to navigate user interface. ${ }^{(42)}$

24. RHAPSODY is a tool designed for caregivers of people with young onset dementia. RHAPSODY has seven modules to provide information and build skills covering the medical nature of young onset dementia, symptom management, relationship management, and self-care activities. ${ }^{(45)}$ 